\title{
A Framework of Creative Education
}

\author{
Kuan Chen Tsai
}

\section{City University of Macau}

\begin{abstract}
The purpose of this article is to propose a theoretical framework for creative education, which consists of three dimensions: initiation, operation, and content. I will first review the creativity literature in education, and then go on to demarcate three levels with several components that are necessary to a pedagogical practice for creative education from the perspectives of psychology. I then discuss the embedded attributes of this framework with further descriptions. Finally, implications for the implementation of the framework are also discussed. It is hoped that this work will encourage and enable more educators to take advantage of the existing literature and transform its insights into practice, thereby boosting students' learning.
\end{abstract}

Keywords: creative education; pedagogy; creativity; theoretical framework

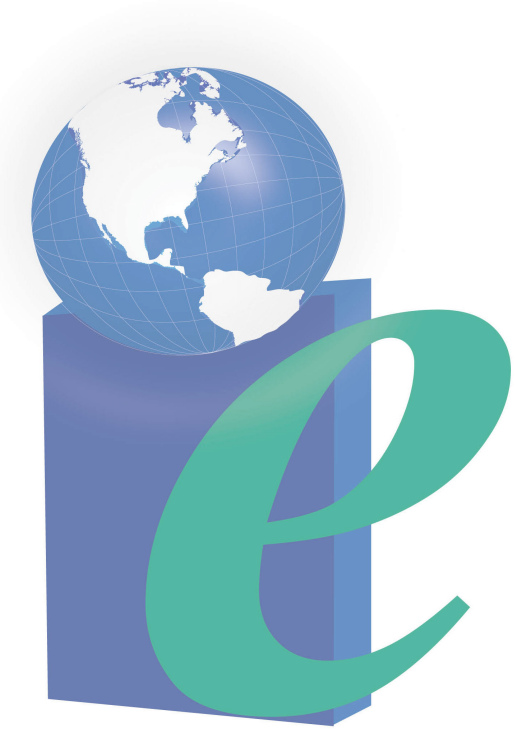




\section{A Framework of Creative Education}

In the educational community, scholars and practitioners have long recognized the necessity of creativity development in children and adults (Feldman \& Benjamin, 2006; Marsiske \& Willis, 1998; Sternberg, 2003; Torrance, 1972; Tsai, 2012a; Westby \& Dawson, 1995). In light of the potential benefits of accessing and using creativity both in learning processes and in daily life, a large number of efforts and major funding have supported the incorporation of creativity into curricula, policy, and experimental learning projects - usually with the expectation that this will reinforce educational reforms (Baer \& Garrett, 2010; Craft, 2010; Haanstra, 1999; Ho \& Ho, 2008; Kim, 2005; Ng, 2003; Runco, 2003). Creativity has also been viewed as an important component of the positive psychology movement, which comprises a variety of cognitive, affective, and interpersonal processes intended to "optimize children's functioning in social domains, academic domains, or artistic domains" (Pearson, Russ, \& Spannagel, 2008, p. 117). In the adult-learning contexts, meanwhile, creativity-centered activities can enhance adults' psychological well-being, personal growth, successful adaption, and sense of fulfillment of life (Flood \& Scharer, 2006; Goff, 1993; Hickson \& Housley, 1997; Tsai, 2013a). Consequently, several educators have urged rethinking adult-learning curricula that can be seen as overemphasizing critical thinking at the expense of the promotion of creative thinking in adult learners (Edelson, 1999; Lones, 2000; Tsai, 2012b).

It would appear that no extant framework is capable of capturing all creative-education scholarship and current practices. In part, this may be because creativity and education scholars tend to have very different beliefs about the nature of creative education, as well as very different views of what creativity for or in education, as a phenomenon, might consist of. The common components mentioned in the proposition and models are characteristics that are positively related to creativity, such as curiosity, open-mindedness, and taking risks. The major difference among scholars is coming from different paradigms to describe the role of creativity

Although it is possible that these rival paradigms could result in a cacophony of outlooks and ideas regarding creative education, it is still worth making a deliberate effort to generate a working framework for synthesizing existing research on creativity and education. It is hoped that via integrating diverse theoretical perspectives on creativity in educational research into a coherent scheme, students as learners and teachers as content deliverers will be able to optimize the expected outcomes of their journeys toward a sound educational practice.

It is important to distinguish carefully between creativity education and creative education. For example, Peng and Plucker (2012) discussed creativity education in China with a focus on promoting creative thinking in educational discourse. In their view, creativity education is parallel to the idea of the important role of creativity in education. Nevertheless, in this article, I use the term creative education from the standpoint of pedagogy. Here, creativity is presented as a means, not an end; it is the use of creative methods to promote students' learning. In other words, creative education could be viewed as the employment of creative means and perspectives in support of the energization of existing educational structures. In this sense, creative education can be broadly defined as creative ways of teaching, thinking, and learning. In order to fulfill that goal, educators should employ different approaches to encourage students to think differently and to learn efficiently. 
The purpose of this article is to propose a theoretical framework for creative education. I will first review the creativity literature in education, and then go on to demarcate three levels with several components that are necessary to a pedagogical practice for creative education. I then discuss the embedded attributes of this framework with further descriptions. Finally, implications for the implementation of the framework are also discussed. It is hoped that this work will encourage and enable more educators to take advantage of the existing literature and transform its insights into practice, thereby boosting students' meaningful learning.

\section{Creativity in Education}

In the United Kingdom, creativity has become the core agenda for educational reform, expanding from the policy level to everyday life as a response to global economic competition and a rapidly changing technological and social milieu (Hall, 2010; Joubert, 2001; Lucas, 2001). The National Advisory Committee on Creative and Cultural Education (NACCCE, 1999) specified four features of creativity - originality, imagination, purpose, and value - and, further, that creativity could be implemented in the classroom via three levels of approaches: creative teaching, teaching creatively, and teaching for creativity. With regard to curriculum design, the Qualifications and Curriculum Authority of the Department for Education and Employment (QCADEE, 1999) suggested five key thinking skills that students should acquire: informationprocessing, reasoning, enquiry, creative thinking, and evaluation skills. Additionally, QCADEE (2000) provided some guidelines for the facilitation of effective creative development, including (a) a stimulating environment in which creativity, originality and expressiveness are valued; (b) sufficient time for children to explore; (c) a wide range of activities that children can respond to by using multiple senses; (d) opportunities for children to express their ideas through a wide range of types of representation; and (e) opportunities to work alongside artists and other creative adults (p. 116).

A similar upward trend in the perceived importance of creativity can also be noted in Taiwanese education. The Ministry of Education (2002) produced a White Paper on Creative Education that strongly supported the development of creativity and innovation, which were recognized as key survival skills in the era of the knowledge economy. The movement for equipping students with creativity and innovation encourages teachers to energize students' learning via two levels of actualization of creativity: enhancing students' creative learning by teachers' creative teaching strategies, and reconstructing the curricula that support the development of creative thinking (Cheng, Wang, Liu, \& Chen, 2010). A series of projects were proposed and implemented experimentally to buttress this educational campaign, but as Cheng and Chen (2010) observe, criteria for the evaluation of the students' learning outcomes are still lacking.

Peng and Plucker (2012) observe that, in general, the educational policies of Chinese societies (China, Hong Kong, Taiwan, and Singapore) are more likely to utilize top-down approaches for promoting creativity, which is from national developmental strategies to local school systems. This contrasts with the United States (U.S.), where the bottom-up approach is more popular (Peng \& Plucker, 2012), and creative-education programs are mostly funded by local independent associations. This discrepancy reflects fundamentally different educational structures, with Chinese societies' educational frameworks being controlled at the national level, and U.S. states having more freedom to choose their own strategic plans. As Marginson's (2011) work observes, Confucian-based cultures tend to be associated with strong nation-state policies 
that shape the structures, funding, and priorities of education. This different approach to strategic planning also reflects cultural variations (e.g., collectivism versus individualism). In any case, the awareness of creativity in education has been widely supported-and creative-education policies implemented to some extent — in both East and West.

Following three principal lines of research on creativity in education, i.e., creative teaching, teaching for creativity, and creative learning (Jeffrey \& Craft, 2004; Lucas, 2001; NACCCE, 1999), Lin (2011) has proposed a framework for creative pedagogy in which each of these three major elements is embedded, forming "a dialogic and improvisational process with creative inspiration, supportive teacher ethos, effective inquiry-based strategies, and learners' creative and autonomous engagement" (p. 153).

Tamdogon (2006), meanwhile, proposes that "creativity in education starts with curiosity" (p. 140). Based on an examination of information circulation and production in lifelong-learning processes, he proposes a "5C" model for creative education, consisting of connectivity, content, community, communication, and commerce. Learning starts with curiosity that triggers questions that are related to the subject (connectivity). In this process, learners, with the help of the teacher, attempt to immerse themselves in the relevant knowledge (content) and try to discern similarities between this content and what they already know (community). After that, alternative answers to the question are proposed, and at the same time, the learners become involved in interactions and exchanges with others in order to validate their opinions (communication). Finally, learners obtain knowledge by examining their perceptions, seeking useful information, and assimilating information linkages, creating personal value via an experience of intellectual transformation (commerce).

It is clear that something is missing from both In Lin's (2011) and Tamdogon's (2006) models of creative education. From the cognitive perspective, at least three levels of learning (affect, behavior, and cognition) should be covered in the model in order to optimize learning outcomes. As such, it is both possible and desirable to construct an alternative model of creative education that includes affective, behavioral, and cognitive perspectives; such a model will be set forth in the next section.

\section{A Model for Creative Education}

Inspired by Guilford's (1950, 1959) structure of intellect model, the conceptual framework I propose consists of three dimensions - initiation, operation, and content - with three components in each dimension, as illustrated in Figure 1. In our exploration of the infinity spiral model, we shall begin curiosity stage, and then teachers might focus on creative thinking with the content of problem solving. However, it is possible that at the beginning teachers stir students' curiosity and welcome students having all kinds of strange ideas without any judgment. When teachers deliver content of information, they can use various creative teaching methods and students might understand the content of information via creative learning. With regard to content of information, teachers might focus on problem finding and problem solving tasks in order to help students more understand the learning material.

For the sake of a sound learning process, I suggest that teachers utilize only those dimensions they feel are relevant to their students. From the affective perspective of psychology, motivation is important for learning and creative performance (Russ, 1993). Therefore, the first step is designed to inspire learners' interest in the subject to be learned. At the same time, teachers 
should be patient and hold positive attitudes toward students' trial-and-error exploration process through cultivating a free discussion environment. In the Operation stage, creativity can function as not only a means but also an end of learning; thus, three interrelated approaches can be used to magnify the learning outcomes. At this point, it is worth raising the important question of what should be taught. Owing to the general purpose of this model, it proposes the teaching of three key skills that will help students to learn across different disciplines. Each component will be further discussed.

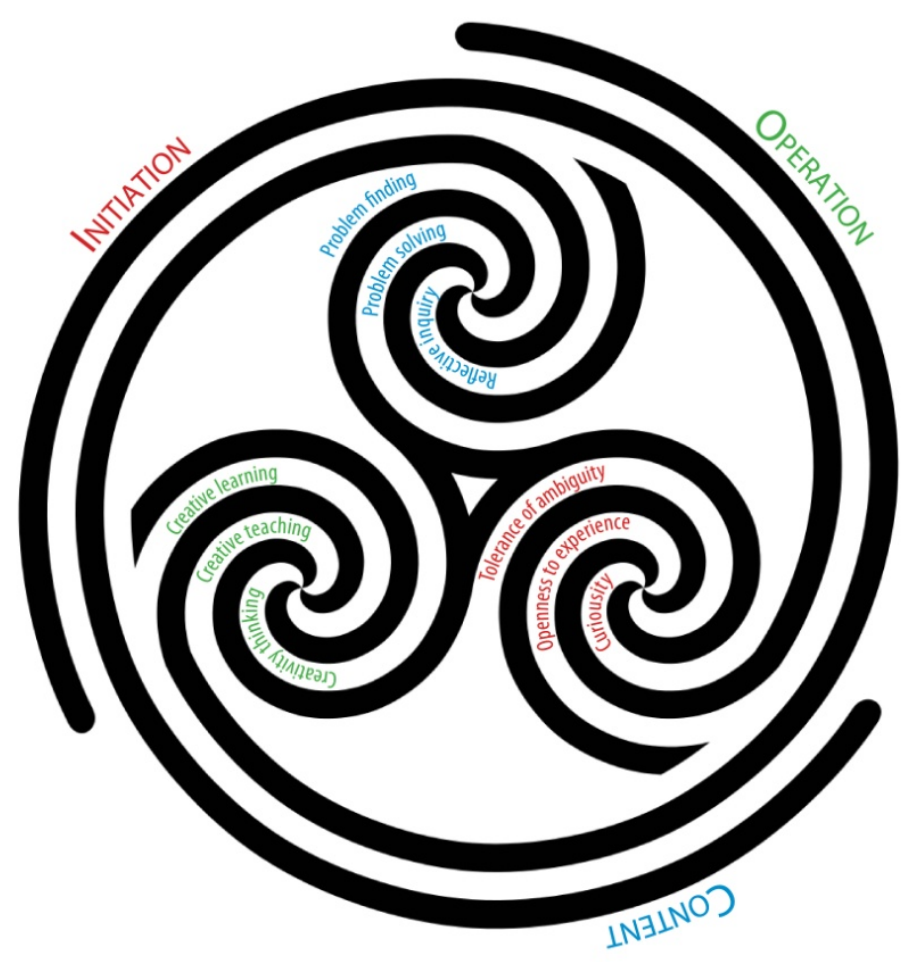

Figure 1. A model of creative education.

\section{Initiation}

Educators regularly find themselves in situations where students are insufficiently motivated to learn new subjects. Exploratory attitudes can have a great deal of utility in enabling students to process knowledge. Therefore, teachers should embrace three behaviors - curiosity, openness to experience, and tolerance of ambiguity - that are central to the first (Initiation) stage of learning, and therefore, to achieving new understanding, interpretations, reflections, and insights.

Curiosity. Hickson and Housley (1997) argue that curiosity and longing for understanding are critical components of the learning processes. Csikszentmihalyi and Nakamura (2006) likewise suggest that creativity is contingent on whether a person is able to "sustain curiosity, interest, and passion" (p. 253). In this sense, curiosity appears to be the first key step for learning and creating. Curiosity has been found to be a key characteristic of the creative personality across different studies (Dineen, Samuel, \& Livesey, 2005; Maksić \& Pavlović, 
2011; Torrance, 1988). It is further speculated that curiosity and playfulness are strongly correlated, and in turn facilitate creative production (Saracho, 2002). Cecil, Gray, Thornburg, and Ispa (1985) find that "curiosity is the arousal state which leads to exploration, play, and creativity" (p. 202). In other words, curiosity can act as a catalyst for increasing one's awareness and consciousness, and then transforming it into a process of discovery. Apart from curiosity's benefits for learning, Oral (2006) suggests that creativity and a sense of wonder can be facilitated by the most original teachers. Restrictions on curiosity are also detrimental to the development and expression of creative thinking (Sternberg \& Lubart, 1995). From a systemic perspective on creativity, Csikszentmihalyi (1999) argues that if one is born in an environment that supports the development of curiosity, then one has a better chance to optimize one's creative performance. The key implication of this statement echoes the important role of teachers in cultivating conditions that are favorable to students thinking "outside of the box." However, openness to experience and tolerance of ambiguity are also important elements in the toolbox, which will be discussed in the next two sections.

Openness to experience. Torrance and Myers (1970) suggest that "the most essential characteristic of self-motivating learning experiences is incompleteness or openness" (p. 53). Openness and flexibility are two important traits that are found in most creative people (Cropley, 1990), and in the creativity research community, flexibility and divergent thinking are viewed as the hallmarks of creativity (Feldhusen \& Goh, 1995; Houtz \& Krug, 1995; Runco, Millar, Acar, $\&$ Cramond, 2010). More fundamentally, the theoretical existence of creativity is closely tied to people's openness, courage, and risk-taking behaviors (Maksić \& Pavlović, 2011). As Feldhusen (2002) wrote, "flexibility as a creativity process...may be chiefly a non-cognitive personality function of openness to diverse information" (p. 181). In other words, for creators, openness to experience may be the key stage in which they assimilate useful information and knowledge, which in turn will become a reservoir for later phases of generating ideas and putting them into practice. Therefore, Taylor (1974) posits "psychological openness" as "an important phase of the process and a necessary condition for creativity" (p. 266). A longitudinal study (cited in Cropley, 2000) showed that children's openness is a valid predictor of adult creative achievement. It is probably the case that keeping an open mind and being sensitive to the environment tend to increase one's imagination, which has also been seen as the foundation of creativity (Misra, Srivastava, \& Misra, 2006).

Tolerance of ambiguity. Lubart and Sternberg (1998) have found that tolerance of ambiguity and risk-taking attitudes vary across different cultures, which may profoundly influence the characteristics of creative production. For example, for Westerners, creativity is often treated as the ability to produce novel and fresh ideas that depart from the norm, and this phenomenon might reflect the ideology of individualism, which tends to encourage people to think freely and explore a wide range of possibilities. Within the cultural framework of Confucianism, in contrast, the view of creativity is more related to adaptation of the norm; it is generally believed that before becoming a true creator, one needs to work hard at mimicry of the classic works until one deeply understands their essence, after which one can gradually transform this level of understanding into creation. The idiom practice makes perfect is deeply rooted in Chinese ways of thinking (Niu \& Kaufman, 2013; Niu \& Sternberg, 2003, 2006; Ng \& Smith, 2004). In summary, openness and tolerance of ambiguity are in fact two sides to one coin, and are often viewed as important components in the facilitation of creativity (Lee \& Seo, 2006; Sternberg, 2003; Urban, 2007). With regard to generating ideas, when people are open to 
different views, they will endure an unclear situation for the moment in order to avoid jumping to conclusions and making decisions too soon. In fact, this is beneficial for the quantity and quality of ideation.

\section{Operation}

There are three important ingredients in the dimension of Operation. Each of them reflects a different perspective on creativity manifested in education. More specifically, these approaches are directly linked to learning processes. Three key ingredients of competitive advantage for learners are seen as likely to evolve via knowledge acquisition, knowledgecreation, and knowledge evaluation. Consequently, teachers should consider creativity in the classroom at least on the three levels discussed in the following sections.

Creative thinking. Runco and Chand (1995) define creative thinking as that which "leads to original and adaptive ideas, solutions, or insights" (p. 224). In creativity research, the investigation of creative thinking has taken two major directions: what variables affect individuals' creative thinking, and what strategies are useful to promote a person's creative thinking. Among the numerous factors that may affect creative thinking, a large number of variables have been identified, including genetics (Runco, et al., 2011), memory (Fauconnier \& Turner, 2002), insight (Finke, 1995), thinking styles (Sternberg, 2006), intelligence (Sternberg, 1985), perception (Turner, 2013), self-efficacy (Beghetto, 2006), motivation (Amabile, 1996), personality (Barron \& Harrington, 1981), moods (Baas, De Dreu, \& Nijstad, 2008), social environment (Csikszentmihalyi, 1996), and culture (Lubart, 1990). As far as creativity training is concerned, several programs and strategies are available in the market, including the Purdue Creative Thinking program (Feldhusen, Treffinger, \& Bahlke, 1970), brainstorming (Meadow, Parnes, \& Reese, 1959), creative problem solving (Treffinger, 1995), SCAMPER (Michalko, 2006), CREATE (Siler, 1996), incubation and imagery (Houtz \& Frankel, 1992), idea checklists (Davis \& Roweton, 1968), ideational skills training (Clapham, 1997), synectics (Gordon, 1961; Koberg, 1973), and play (Tsai, 2012c). Scott, Leritz, and Mumford's (2004) meta-analytic review of creativity, suggests that in order to maximize the success of training, it should be (a) based on valid conceptions of the cognitive activities that relate to creative efforts, (b) related to heuristics and various cognitive skills, and (c) implemented in light of real-world cases and contexts and followed by a series of appropriate exercises. In addition, Torrance (1972) believed that the most successful strategies for teaching creative thinking should "involve both cognitive and emotional functioning, provide adequate structure and motivation, and give opportunities for involvement, practice, and interaction between teachers and students" (p. 9).

Creative teaching. NACCCE (1999) views creative teaching from two perspectives: teaching creatively, which means teachers employ "imaginative approaches to make learning more interesting, exciting, and effective" (p. 102), and teaching for creativity, that is for the purpose of developing learners' creative thinking. Creative teaching has been defined as "a unique, customized, and meaningful exchange of knowledge among all individuals in a learning context" (Rinkevich, 2011, p. 219). More broadly, it has been called an "invigorating, exciting, innovative, and engaging pedagogy" (Craft, 2011, p. 129), and a form of "disciplined improvisation" (Sawyer, 2010, p. 185) in which teachers use creative ways of imparting knowledge, which in turn leads to empowered learners (Jeffrey \& Craft, 2004). Rinkevich (2011) argues that the promotion and understanding of creativity in teaching should begin in teacher education and continue through professional development. One case study of creative teachers 
(Bramwell, Reilly, Lilly, Kronish, \& Chennabathni, 2011) indicates that these teachers were highly motivated and passionate about their work, as well as being risk-takers, who valued intellectual activity. Another case study, of three creative Taiwanese teachers (Horng, Hong, ChanLin, Chang, \& Chu, 2005), found that these teachers used several salient strategies in their classroom: student-centered learning, the use of multiple teaching aids, class-management strategies, drawing connections between teaching content and real life, and the use of open questions in the encouragement of creative thinking (pp. 356-357). In short, it is hard to disagree with Burnard (2012), that "teaching is a complex task involving a high degree of creativity" ( $p$. 167). Teachers in fact continuously construct their creative-teaching approach by engaging students in thinking about "resources, ideas, mediums, and patterns" (Jeffrey, 2006, p. 407). The key assumption rooted in the notion of creative teaching is open adventures involving information and knowledge.

Creative learning. In contrast to the teacher-focus of creative teaching, the idea of creative learning is learner-centered. Creative learning is interactive and encourages learners to experiment and explore possible learning approaches with an attitude of playfulness. The ultimate goal of creative learning is to unleash an individual's potential (Banaji, 2011; SeftonGreen \& Bresler, 2011), though at its heart are "the long-term habits of playfulness" (SeftonGreen, Thomson, Jones, \& Bresler, 2011, p. 5) is at heart of creative learning. Students first should know their respective learning styles and understand what factors may slow their learning curve. To overcome fixed obstacles to their learning process, a series of experiments and play with alternatives is necessary. In fact, as Wiggins (2011) points out, "creative learning is only elicited and developed when the learner is confronted with one novel challenge after another, interspersed with feedback and focused direct instruction" (p. 322). Thus, the author maintains, teachers should design curricula that frame demanding questions, and problems that challenge students in the broadest sense. Burnard (2011) remarks that creative learning should be manifested at every stage in processing knowledge, with students asking questions, making connections, generating ideas, exploring options, and evaluating their results. Treffinger's (2004) model of creative learning is composed of three levels: learning basic thinking tools, learning and practicing problem-solving models, and dealing with real problems and challenges (p. 90). This echoes Sternberg and O'Hara's (2000) argument, that "creativity seems to involve synthetic, analytical, and practical aspects of intelligence" (p. 627). It would appear that, in order to maximize creative learning, students first should learn the four fundamental thinking strategies: analytical thinking, reasoning skills, creative thinking, and critical thinking. Then they can master these tools by practicing using artificial problems. Finally, they can transform these capacities for use in their real-life situations, thus completing a full-circle learning experience.

\section{Content}

What capacities students should learn is of great concern to educators. In order to facilitate the acquisition of necessary skills that can be used across diverse subjects, it is useful to employ a general guideline. The three abilities that will be discussed below are thought to be the core stages of successful creators' achievements.

Problem finding. Csikszentmihalyi (1988) suggests that problem finding and problem solving might require opposite cognitive strategies. As Mackworth (1965) puts it, "problem solving is a choice between existing programs or sets of mental rules, whereas problem finding is the detection of the need for a new program based on a choice between existing and expected 
future programs" (p. 57). Mackworth further suggests that problem finding may be most closely related to originality in creative thinking in science. More specifically, for creative achievements, problem solving is necessary but not sufficient; rather, these achievements might largely rely on the discovery of problems, which is often a restriction of the problem by viewing things from different perspectives (Dillon, 1982; Runco \& Sakamoto, 1999). The results of one study (Starko, 1989) focused on problem finding in creative writing showed that discovery-oriented behavior plays an important role for professional writers in the stage of manipulation of different ideas and seeking new combinations. Several models of the creative process have identified the recognition of problems as the first important step to creatively solve problems, and have suggested that problem-finding ability may be more difficult to cultivate than problem-solving ability (Lubart, 2001; Mumford, 2003). Runco and Okuda (1988) also recognize the importance of problem discovery to creativity, due to its occurrence at a very early stage, which leads it (at least partially) to affect the quality of the ensuing solutions. Probably the most widely known creativity-training program - Creative Problem Solving (CPS) — outlines six steps for effectively generating solutions and solving problems: mess finding, data finding, problem finding, idea finding, solution finding, and acceptance finding (Baer \& Kaufman, 2006). Mumford and colleagues (1991) proposed several core processes in creative problem solving, including problem construction, category search, specification of categories, idea evaluation, and actual implementation. This model highlights the importance of convergent and divergent processes, and holds that problem construction, category search, and category combination in particular are essential for generating new ideas.

Problem solving. Despite the important work that has been done on problem finding, problem solving is still widely viewed as the most important topic in creativity scholarship (Hennessey \& Amabile, 2010; Mayer, 1995; Nickerson, 1999; Simonton, 2006; Torrance, 1995). Indeed, for most psychologists, "problem solving has taken first place as almost synonymous with creative thinking" (Gruber, 1996, p. 251). From the viewpoint of Gestalt psychologists, insight is an important aspect of problem solving, whereby people go beyond their experience and overcome misleading facts by restructuring the presentation of a problem (Dominowski \& Dallob, 1995). Incubation is another well-known factor that has been used to explain the process of creative problem solving. According to Wallas's (1926) classic theory, a problem is successfully solved via four stages: preparation, incubation, illumination, and verification. He hypothesized that in order to find a solution a person will unconsciously undergo a period of mental work to obtain the inspiration, which he called incubation.

Most models of creative problem solving, in short, emphasize either a hierarchical or nonlinear stage decomposition (Hélie \& Sun, 2010). One of the most influential theories of creativity is known as Geneplore (Finke, Ward, \& Smith, 1992), which proposes that the creative process consist of two distinct components: a generative process and an exploratory process. The first stage is to construct mental representation via memory retrieval, association, and analogy. Then, these pre-inventive structures are transferred into the exploration-a process of interpretation and evaluation - by means of attribute finding, conceptual interpretation, and hypothesis testing to interpret and evaluate these structures. Mumford and Gustafson (1988) contend that creativity can be viewed as a syndrome involving five attributes: (a) the process underlying the individual's capacity to generate new ideas or understandings; (b) the characteristics of the individual facilitating process of various ideas; (c) the characteristics of the individual that facilitate the translation of these ideas into action; (d) the attributes of the 
situation conditioning the individual's willingness to engage in creative behavior; and (e) the attributes of the situation influencing evaluation of the individual's productive efforts (p. 28). In this conspectus, it seems clear that idea generation and problem solving are the most important aspects of the agenda for creativity. In short, from the cognitive perspective of the creative process, two key cognitive elements are usually highlighted: conceptual combination and idea generation (Mumford, 2003). According to Scott et al.'s (2004) meta-analysis of creativitytraining studies, the most clear-cut results indicate that problem finding, conceptual combination, and idea generation are the three most powerful influences on the effectiveness of creativity training. Thus, these authors suggest that when developing, and providing guidance for, any creativity training program, it is necessary to consider these cognitive.

Reflective inquiry. Basadur, Graen, and Green (1982) note that "creativity processes which take into account evaluation and go beyond solution finding to problem finding and implementation considerations are termed complete processes" (p. 44). It is clear that critical evaluation of ideas and solutions is crucial to creative achievements. Basadur, Pringle, and Kirkland (2002) suggest, with regard to the traditional three phases of the problem-solving process (problem finding, problem solving, and solution implementation), that another two-step ideation evaluation is needed in each of three phases. These are (a) active divergence, (b) active convergence, and (c) deferring convergence. In these authors' view, evaluation and reflection should occur during each stage on the path toward the eventual production of creative products, enabling a full-cycle creative process. According to Runco and Chand's (1995) two-tier model of creative thinking, the three components of problem finding, ideation, and evaluation are all assigned to the first tier, while the second tier consists of knowledge and motivation. Basadur, Runco, and Vega (2000) found that when their subjects' evaluation skills increased, they tended to avoid premature convergence, which led - albeit indirectly - to them generating more ideas.

In adult learning literature, critical thinking de facto is an important component of curriculum development (Brookfield, 1986). Brookfield (2012) provides useful insights and tactics to bring critical thinking into the classroom. For instance, he uses the Critical Incident Questionnaire (CIQ) as a classroom evaluation tool in his teaching, with five questions asking students to reflect on their learning experience:

- At what moment were you most engaged as a learner?

- At what moment were you most distanced as a learner?

- What action that anyone took in class did you find most helpful?

- What action that anyone took in class did you find most confusing?

- What surprised you most about the class? (p. 54)

In short, critical thinking and creative thinking may not, in fact, be contradictory but complementary (Tsai, 2013b). In order to secure a higher quality of creative outputs, serious reflection upon and assessment of each idea is necessary; and thus it should not be surprising that the journey of writers' and artists' work from the idea stage to public release/exhibition is so often a long and arduous one. Until that point, everything is a draft, unworthy of sharing with strangers.

In summary, the essence of the framework presented in this article is grounded in the idea that not only the strategies employed by teachers, but also the attitudes they embrace have learning effects on students. More specifically, the success of education is not solely dependent 
upon teachers' or students' ability to develop and execute effective strategies, but also upon how both these groups discover and face new opportunities and resources for the expansion of existing knowledge. However, knowledge of opportunities and access to resources are not normally distributed in the existing educational framework; rather, opportunities appear to come to students at key informational loci within the existing educational hierarchy. Ideally, from a social-capital perspective, education should act as a channel for social mobility, and facilitate resource sets for the best exploitation of educational possibilities amid ongoing change and competition in a society (Tsai \& Ozturgut, 2013).

\section{Conclusions}

Before turning to the broader conclusions deriving from this article, certain limitations should be noted. To begin, this article was based on a psychological paradigm where creativity was studied in a cognitive framework. As a result, the propositions obtained in this effort do not speak to other possible variables in the education, such as curriculum design, classroom management, school policy, and so on. Although this cognitive paradigm has certain advantages, it is still unclear what will happen when employing this model in real-world settings. Along this line, it should be recognized that this working model needs to be verified by other empirical studies. Therefore, it is urged that other researchers and educators view this model as the first step and actualize this model to their studies and classrooms. This universal model does not consider culture. Indeed, differences do exist related to issues of good practice in education. Thus, this model should also be examined by cross-cultural studies.

In my attempts to locate the story of creative education, I have encountered many premature ideas and versions on the way to constructing this conceptual framework. Its theoretical roots stems from a psychological approach that celebrates the dynamic processes of constructing knowledge creatively. As the preceding remarks implicitly suggest, this working framework is still far from complete, due to the manifest complexity of creative education itself. Nevertheless, it provides a good starting point for rethinking our current educational assumptions, and potentially, for mapping what human capital we want to see in the next generation. For example, with the application of the proposed model, I suggest that educators consider three dimensions of teaching process from the Initiation level that stirs up students involving in the subject discussion and preparing for further learning. Teaching and learning is a two-way street. Thus, in the next Operation level, it is plausible that the interplay between teachers' creative teaching and students' creative learning can reinforce the positive experience of learning, and creative thinking mediates this relationship. Whether creative teaching, or creative learning, or creative thinking, it is teachers' responsibility to nurture this ability for themselves and their students through different strategies and deliberate practice. So what content-area teachers should teach across different disciplines? As the proposed model suggested, problem identification, problem solving, and reflective inquiry are three main lines of the creation of new knowledge and processing information. Of course, it still needs further study to confirm the reliability and validity of the proposed working model. In short, the major purpose of this article is to indicate that the direction of creative education research has important implications for education scholarship and leadership that cannot be ignored. 


\section{References}

Amabile, T. M. (1996). Creativity in context: Update to the social psychology of creativity. Boulder, CO: Westview Press.

Baas, M., De Dreu, C. W., \& Nijstad, B. A. (2008). A meta-analysis of 25 years of moodcreativity research: Hedonic tone, activation, or regulatory focus? Psychological Bulletin, 134(6), 779-806.

Baer, J., \& Garrett, T. (2010). Teaching for creativity in an era of content standards and accountability. In R. A. Beghetto \& J. C. Kaufman (Eds.), Nurturing creativity in the classroom (pp. 6-23). New York, NY: Cambridge University Press.

Baer, J., \& Kaufman, J. C. (2006). Creativity research in English-speaking countries. In J. C. Kaufman \& R. J. Sternberg (Eds.), The international handbook of creativity (pp. 10-38). New York, NY: Cambridge University Press.

Banaji, S. (2011). Mapping the rhetorics of creativity. In J. Sefton-Green, P. Thomson, K. Jones, \& L. Bresler (Eds.), The Routledge international handbook of creative learning (pp. 3644). New York, NY: Routledge.

Barron, F., \& Harrington, D. M. (1981). Creativity, intelligence, and personality. Annual Review of Psychology, 32(1), 439-476.

Basadur, M., Graen, G. B., \& Green, S. G. (1982). Training in creative problem solving: Effects on ideation and problem finding and solving in an industrial research organization. Organizational Behavior and Human Performance, 30(1), 41-70.

Basadur, M., Pringle, P., \& Kirkland, D. (2002). Crossing cultures: Training effects on the divergent thinking attitudes of Spanish-speaking South American managers. Creativity Research Journal, 14(3/4), 395-408.

Basadur, M., Runco, M. A., \& Vega, L. A. (2000). Understanding how creative thinking skills, attitudes, and behaviors work together: A casual process model. The Journal of Creative Behavior, 34(2), 77-100.

Beghetto, R. A. (2006). Creative self-efficacy: Correlates in middle and secondary students. Creativity Research Journal, 18(4), 447-457.

Bramwell, G., Reilly, R. C., Lilly, F. R., Kronish, N., \& Chennabathni, R. (2011). Creative teachers. Roeper Review, 33(4), 228-238.

Brookfield, S. D. (1986). Understanding and facilitating adult learning: A comprehensive analysis of principles and effective practices. San Francisco, CA: Jossey-Bass.

Brookfield, S. D. (2012). Teaching for critical thinking: Tools and techniques to help students question their assumptions. San Francisco, CA: Jossey-Bass.

Burnard, P. (2011). Constructing assessment for creative learning. In J. Sefton-Green, P. Thomson, K. Jones, \& L. Bresler (Eds.), The Routledge international handbook of creative learning (pp. 140-149). New York, NY: Routledge. 
Burnard, P. (2012). Rethinking creative teaching and teaching as research: Mapping the critical phases that mark times of change and choosing as learners and teachers of music. Theory Into Practice, 51(3), 167-178.

Cecil, L. M., Gray, M. M., Thornburg, K. R., \& Ispa, J. (1985). Curiosity-exploration-playcreativity: The early childhood mosaic. Early Child Development and Care, 19(3), 199217.

Cheng, K.-W., \& Chen, T.-F. (2010). Developing and verifying a business-creativity assessment tool: A nationwide study in Taiwan. Journal of Education for Business, 85(1), 78-84.

Cheng, Y.-Y., Wang, W.-C., Liu, K.-S., \& Chen, Y.-L. (2010). Effects of association instruction on fourth graders' poetic creativity in Taiwan. Creativity Research Journal, 22(2), 228 235.

Clapham, M. M. (1997). Ideational skills training: A key element in creativity training programs. Creativity Research Journal, 10(1), 33-44.

Craft, A. (2010). Possible thinking and wise creativity: Educational features in England. In R. A. Beghetto \& J. C. Kaufman (Eds.), Nurturing creativity in the classroom (pp. 289-312). New York, NY: Cambridge University Press.

Craft, A. (2011). Approaches to creativity in education in the United Kingdom. In J. SeftonGreen, P. Thomson, K. Jones, \& L. Bresler (Eds.), The Routledge international handbook of creative learning (pp. 129-139). New York, NY: Routledge.

Cropley, A. J. (1990). Creativity and mental health in everyday life. Creativity Research Journal, 3(3), 167-178.

Cropley, A. J. (2000). Defining and measuring creativity: Are creativity tests worth using? Roeper Review, 23(2), 72-79.

Csikszentmihalyi, M. (1988). Solving a problem is not finding a new one: A reply to Simon. New Ideas in Psychology, 6(2), 183-186.

Csikszentmihalyi, M. (1996). Creativity: Flow and the psychology of discovery and invention. New York, NY: HarperCollins.

Csikszentmihalyi, M. (1999). Implications of a systems perspective for the study of creativity. In R. J. Sternberg (Ed.), Handbook of creativity (pp. 313-335). New York, NY: Cambridge University Press.

Csikszentmihalyi, M., \& Nakamura, J. (2006). Creativity through the life span from an evolutionary systems perspective. In C. Hoare (Ed.), Handbook of adult development and learning (pp. 243- 254). New York, NY: Oxford University Press.

Davis, G. A., \& Roweton, W. E. (1968). Using idea checklists with college students: Overcoming resistance. The Journal of Psychology, 70(1), 221-226.

Dillon, J. T. (1982). Problem finding and solving. The Journal of Creative Behavior, 16(2), 97111. 
Dineen, R., Samuel, E., \& Livesey, K. (2005). The promotion of creativity in learners: Theory and practice. Art, Design \& Communication in Higher Education, 4(3), 155-172.

Dominowski, R. L., \& Dallob, P. (1995). Insight and problem solving. In R. J. Sternberg \& J. E. Davidson (Eds.), The nature of insight (pp. 33-62). Cambridge, MA: The MIT Press.

Edelson, P. J. (1999). Creativity and adult education. New Directions for Adult \& Continuing Education, 81(1), 3-13.

Fauconnier, G., \& Turner, M. (2002). The way we think: Conceptual blending and the mind's hidden complexities. New York, NY: Basic Books.

Feldhusen, J. F. (2002). Creativity: The knowledge base and children. High Ability Studies, 13(2), 179-183.

Feldhusen, J. F., \& Goh, B. E. (1995). Assessing and accessing creativity: An integrative review of theory, research, and development. Creativity Research Journal, 8(3), 231-247.

Feldhusen, J. F., Treffinger, D. J., \& Bahlke, S. J. (1970). Developing creative thinking: The Purdue Creative Thinking program. The Journal of Creative Behavior, 4(2), 85-90.

Feldman, D., \& Benjamin, A. C. (2006). Creativity and education: An American retrospective. Cambridge Journal of Education, 36(3), 319-336.

Finke, R. A. (1995). Creative insight and preinventive forms. In R. J. Sternberg \& J. E. Davidson (Eds.), The nature of insight (pp. 255-280). Cambridge, MA: The MIT Press.

Finke, R. A., Ward, T. B., \& Smith, S. M. (1992). Creative cognition: Theory, research, and applications. Cambridge, MA: The MIT Press.

Flood, M., \& Scharer, K. (2006). Creativity enhancement: Possibilities for successful aging. Issues in Mental Health Nursing, 27(9), 939-959.

Goff, K. (1993). Creativity and life satisfaction of older adults. Educational Gerontology, 19(3), 241-250.

Gordon, W. J. J. (1961). Synectics: The development of creative capacity. New York, NY: Harper \& Row.

Gruber, H. E. (1996). The life space of a scientist: The visionary function and other aspects of Jean Piaget's thinking. Creative Research Journal, 9(2/3), 251-265.

Guilford, J. P. (1950). Creativity. American Psychologist, 5(9), 444-454.

Guilford, J. P. (1959). Three faces of intellect. American Psychologist, 14(8), 469-479.

Haanstra, F. H. (1999). The Dutch experiment in developing adult creativity. New Directions for Adult \& Continuing Education, 81(1), 37-45.

Hall, C. (2010). Creativity in recent educational discourse in England. World Englishes, 29(4), 481-492. 
Hélie, S., \& Sun, R. (2010). Incubation, insight, and creative problem solving: A unified theory and a connectionist model. Psychological Review, 117(3), 994-1024.

Hennessey, B. A., \& Amabile, T. M. (2010). Creativity. Annual Review of Psychology, 61(1), 569-598.

Hickson, J., \& Housley, W. (1997). Creativity in later life. Educational Gerontology, 23(6), 539547.

Ho, D. Y. F., \& Ho, R. T. H. (2008). Knowledge is a dangerous thing: Authority relations, ideological conservatism, and creativity in Confucian-heritage cultures. Journal for the Theory of Social Behaviour, 38(1), 67-86.

Horng, J.-S., Hong, J.-C., ChanLin, L.-J., Chang, S.-H., \& Chu, H.-C. (2005). Creative teachers and creative teaching strategies. International Journal of Consumer Studies, 29(4), 352 358.

Houtz, J. C., \& Frankel, A. D. (1992). Effects of incubation and imagery training on creativity. Creativity Research Journal, 5(2), 183-189.

Houtz, J. C., \& Krug, D. (1995). Assessment of creativity: Resolving a mid-life crisis. Educational Psychology Review, 7(3), 269-300.

Jeffrey, B. (2006). Creative teaching and learning: Towards a common discourse and practice. Cambridge Journal of Education, 36(3), 399-414.

Jeffrey, B., \& Craft, A. (2004). Teaching creatively and teaching for creativity: Distinctions and relationships. Educational Studies, 30(1), 77-87.

Joubert, M. M. (2001). The art of creative teaching: NACCCE and beyond. In A. Craft, B. Jeffrey, \& M. Leibling (Eds.), Creativity in education (pp. 17-34). New York, NY: Continuum.

Kim, K. H. (2005). Learning from each other: Creativity in east Asian and American education. Creativity Research Journal, 17(4), 337-347.

Koberg, D. (1973). The universal traveler: A soft-systems guide to creativity, problem-solving, and the process of design. Los Altos, CA: William Kaufmann.

Lee, E. A., \& Seo, H. A. (2006). Understanding of creativity by Korean elementary teachers in gifted education. Creativity Research Journal, 18(2), 237-242.

Lin, Y. S. (2011). Fostering creativity through education: A conceptual framework of creative pedagogy. Creative Education, 2(3), 149-155.

Lones, P. S. (2000). Learning as creativity: Implications for adult learners. Adult Learning, 11(4), 9-12.

Lubart, T. I. (1990). Creativity and cross-cultural variation. International Journal of Psychology, 25(1), 39-59.

Lubart, T. I. (2001). Models of the creative process: Past, present and future. Creativity Research Journal, 13(3/4), 295-308. 
Lubart, T. I., \& Sternberg, R. J. (1998). Creativity across time and place: Life span and crosscultural perspectives. High Ability Studies, 9(1), 59-74.

Lucas, B. (2001). Creative teaching, teaching creativity and creative learning. In A. Craft, B. Jeffrey, \& M. Leibling (Eds.), Creativity in education (pp. 35-44). New York, NY: Continuum.

Mackworth, N. H. (1965). Originality. American Psychologist, 20(1), 51-66.

Maksić, S., \& Pavlović, J. (2011). Educational researchers' personal explicit theories on creativity and its development: A qualitative study. High Ability Studies, 22(2), 219-231.

Marginson, S. (2011). Higher education in East Asia and Singapore: Rise of the Confucian model. High Education, 61(1), 587-611.

Marsiske, M., \& Willis, S. L. (1998). Practical creativity in older adults' everyday problem solving: Life span perspectives. In C. E. Adams-Price (Ed.), Creativity and successful aging: Theoretical and empirical approaches (pp. 73-113). New York, NY: Springer.

Mayer, R. E. (1995). The search for insight: Grappling with Gestalt psychology's unanswered questions. In R. J. Sternberg \& J. E. Davidson (Eds.), The nature of insight (pp. 3-32). Cambridge, MA: The MIT Press.

Meadow, A., Parnes, S. J., \& Reese, H. (1959). Influence of brainstorming instructions and problem sequence on a creative problem solving test. Journal of Applied Psychology, 43(6), 413-416.

Michalko, M. (2006). Thinkertoys: A handbook of creative-thinking techniques. New York, NY: Ten Speed Press.

Ministry of Education (2002). White paper on creative education: Establishing a republic of creativity for Taiwan. Taipei: Author.

Misra, G., Srivastava, A. K., \& Misra, I. (2006). Culture and facets of creativity. In J. C. Kaufman \& R. J. Sternberg (Eds.), The international handbook of creativity (pp. 421455). New York, NY: Cambridge University Press.

Mumford, M. D. (2003). Where have we been, where are we going? Taking stock in creativity research. Creativity Research Journal, 15(2/3), 107-120.

Mumford, M. D., \& Gustafson, S. B. (1988). Creativity syndrome: Integration, application, and innovation. Psychological Bulletin, 103(1), 27-43.

Mumford, M. D., Mobley, M. I., Uhlman, C. E., Reiter-Palmon, R., \& Doares, L. M. (1991). Process analytic models of creative capacities. Creativity Research Journal, 4(2), 91-122.

National Advisory Committee on Creative and Cultural Education (1999). All our futures: Creativity, culture \& education. Sudbury, Suffolk: Department for Education and Employment.

Nickerson, R. S. (1999). Enhancing creativity. In R. J. Sternberg (Ed.), Handbook of creativity (pp. 392-430). New York, NY: Cambridge University Press. 
$\mathrm{Ng}$, A. K. (2003). A cultural model of creative and conforming behavior. Creativity Research Journal, 15(2/3), 223-233.

Ng, A. K., \& Smith, I. (2004). The paradox of promoting creativity in the Asian classroom: An empirical investigation. Genetic, Social \& General Psychology Monographs, 130(4), 307-330.

Niu, W., \& Kaufman, J. C. (2013). Creativity of Chinese and American Cultures: A synthetic analysis. The Journal of Creative Behavior, 47(1), 77-87.

Niu, W., \& Sternberg, R. J. (2003). Societal and school influences on student creativity: The case of China. Psychology in the Schools, 40(1), 103-114.

Niu, W., \& Sternberg, R. J. (2006). The philosophical roots of Western and Eastern conceptions of creativity. Journal of Theoretical and Philosophical Psychology, 26(1), 18-38.

Oral, G. (2006). Creativity of Turkish prospective teachers. Creativity Research Journal, 18(1), 65-73.

Pearson, B. L., Russ, S. W., \& Spannagel, S. (2008). Pretend play and positive psychology: Natural companions. Journal of Positive Psychology, 3(2), 110-119.

Peng, W., \& Plucker, J. A. (2012). Recent transformation in China's economic, social, and education policies for promoting innovation and creativity. The Journal of Creative Behavior, 46(4), 247-273.

Qualifications and Curriculum Authority/Department for Education and Employment (1999). The national curriculum handbook for primary teachers in England. London, UK: DfEE/QCA.

Qualifications and Curriculum Authority/Department for Education and Employment (2000). Curriculum guidance for the foundation stage. London, UK: DfEE/QCA.

Rinkevich, J. L. (2011). Creative teaching: Why it matters and where to begin. The Clearing House: A Journal of Educational Strategies, Issues and Ideas, 84(5), 219-223.

Runco, M. A. (2003). Education for creative potential. Scandinavian Journal of Educational Research, 47(3), 317-324.

Runco, M. A., \& Chand, I. (1995). Cognition and creativity. Educational Psychology Review, $7(3), 243-267$.

Runco, M. A., Millar, G., Acar, S., \& Cramond, B. (2010). Torrance Test of Creative Thinking as predictors of personal and public achievement: A fifty-year follow-up. Creativity Research Journal, 22(4), 361-368.

Runco, M. A., Noble, E. P., Reiter-Palmon, R., Acar, S., Ritchie, T., \& Yurkovich (2011). The genetic basis of creativity and ideational fluency. Creativity Research Journal, 23(4), 376-380.

Runco, M. A., \& Okuda, S. M. (1988). Problem discovery, divergent thinking, and the creative process. Journal of Youth and Adolescence, 17(3), 211-220. 
Runco, M. A., \& Sakamoto, S. O. (1999). Experimental studies of creativity. In R. J. Sternberg (Ed.), Handbook of creativity (pp. 62-92). New York, NY: Cambridge University Press.

Russ, S. W. (1993). Affect and creativity: The role of affect and play in the creative process. Hillsdale, NJ: Lawrence Erlbaum Associates.

Saracho, O. (2002). Young children's creativity and pretend play. Early Child Development \& Care, 172(5), 431-438.

Sawyer, R. K. (2010). Learning for creativity. In R. A. Beghetto \& J. C. Kaufman (Eds.), Nurturing creativity in the classroom (pp. 172-190). New York, NY: Cambridge University Press.

Scott, G., Leritz, L. E., \& Mumford, M. D. (2004). The effectiveness of creativity training: A quantitative review. Creativity Research Journal, 16(4), 361-388.

Sefton-Green, J. \& Bresler, L. (2011). Theories and histories: Creative learning and its contexts. In J. Sefton-Green, P. Thomson, K. Jones, \& L. Bresler (Eds.), The Routledge international handbook of creative learning (pp. 9-14). New York, NY: Routledge.

Sefton-Green, J., Thomson, P., Jones, K., \& Bresler, L. (2011). Introduction. In J. Sefton-Green, P. Thomson, K. Jones, \& L. Bresler (Eds.), The Routledge international handbook of creative learning (pp. 1-8). New York, NY: Routledge.

Siler, T. (1996). Think like a genius. New York, NY: Bantam.

Simonton, D. K. (2006). Creativity around the world in 80 ways... but with one destination. In J. C. Kaufman \& R. J. Sternberg (Eds.), The international handbook of creativity (pp. 490496). New York, NY: Cambridge University Press.

Starko, A. J. (1989). Problem finding in creative writing: An exploratory study. Journal for the Education of the Gifted, 7(3), 172-186.

Sternberg, R. J. (1985). Beyond IQ: A triarchic theory of human intelligence. New York, NY: Cambridge University Press.

Sternberg, R. J. (2003). Creative thinking in the classroom. Scandinavian Journal of Educational Research, 47(3), 325-338.

Sternberg, R. J. (2006). The nature of creativity. Creativity Research Journal, 18(1), 87-98.

Sternberg, R. J., \& Lubart, T. I. (1995). Defying the crowd: Cultivating creativity in a culture of conformity. New York, NY: The Free Press.

Sternberg, R. J., \& O’Hara, L. A. (2000). Intelligence and creativity. In R. J. Sternberg (Ed.), Handbook of intelligence (pp. 611-630). New York, NY: Cambridge University Press.

Tamdogon, O. G. (2006). Creativity in education: Clearness in perception, vigorousness in curiosity. Education for Information, 24(1), 139-151.

Taylor, I. A. (1974). Developing creativity in gifted young adults. Education, 94(3), 266-268. 
Torrance, E. P. (1972). Can we teach children to think creatively? Journal of Creative Behavior, 6(1), 114-143.

Torrance, E. P. (1988). The nature of creativity as manifest in its test. In R. J. Sternberg (Ed.), The nature of creativity: Contemporary psychology perspectives (pp. 43-75). New York: Cambridge University Press.

Torrance, E. P. (1995). Why fly? A philosophy of creativity. Norwood, NJ: Ablex.

Torrance, E. P., \& Myers, R. E. (1970). Creative learning and teaching. New York, NY: Dodd, Mead \& Company.

Treffinger, D. J. (1995). Creative problem solving: Overview and educational implications. Educational Psychology Review, 7(3), 301-312.

Treffinger, D. J. (2004). Research on creativity. In D. J. Treffinger (Ed.), Creativity and giftedness (pp. 87-96). Thousand Oaks, CA: Corwin Press.

Tsai, K. C. (2012a). The value of teaching creativity in adult education. International Journal of Higher Education, 1(2), 84-91.

Tsai, K. C. (2012b). Bring creativity into the adult classroom: An investigative study. Review of Higher Education and Self-Learning, 5(16), 67-78.

Tsai, K. C. (2012c). The efficacy of play on divergent thinking of adult learners. Journal of Studies in Education, 2(4), 67-78.

Tsai, K. C. (2013a). A review of the inquiry of creativity in older adults in journals. British Journal of Education, 1(2), 20-28.

Tsai, K. C. (2013b). Being a critical and creative thinker: A balanced thinking mode. Asian Journal of Humanities and Social Sciences, 1(2), 1-9.

Tsai, K. C., \& Ozturgut, O. (2013). PISA and beyond: What can we learn from Asian education. Pacific-Asian Education, 25(2), 5-16.

Turner, S. (2013). Teachers' and pupils' perceptions of creativity across different key stages. Research in Education, 89(1), 23-40.

Urban, K. K. (2007). Assessing creativity: A componential model. In A.G. Tan (Ed.), Creativity: A handbook for teachers (pp.167-184). Hackensack, NJ: World Scientific Publishing.

Wallas, G. (1926). The art of thought. New York, NY: Harcourt Brace Jovanovich.

Westby, E. L., \& Dawson, V. L. (1995). Creativity: Asset or burden in the classroom? Creativity Research Journal, 8(1), 1-10.

Wiggins, G. (2011). Creative learning. In J. Sefton-Green, P. Thomson, K. Jones, \& L. Bresler (Eds.), The Routledge international handbook of creative learning (pp. 320-331). New York, NY: Routledge. 